ECCOMAS

Proceedia
COMPDYN 2021

$8^{\text {th }}$ ECCOMAS Thematic Conference on Computational Methods in Structural Dynamics and Earthquake Engineering

M. Papadrakakis, M. Fragiadakis (eds.) Streamed from Athens, Greece, 28 - 30 June 2021

\title{
ANALYSIS OF GEOMETRICALLY NON-LINEAR FREE VIBRATIONS OF FUNCTIONAL GRADED BEAMS IN A THERMAL ENVIRONMENT
}

\author{
Y. EI khouddar ${ }^{1}$, A. Adri ${ }^{1}$, O. Outassafte ${ }^{1}$, S. Rifai ${ }^{1}$ and R. Benamer ${ }^{2}$ \\ ${ }^{1}$ Laboratoire de Mécanique Productique e é ie Industriel, Ecole Supérieure de Technologie, Hassan II Uni- \\ versity of Casablatnca, B.P.8012, Oasis, Casablanca, Morocco \\ e-mail: yassine.elkhouddar@ensem.ac.ma, ahmedadri@gmail.com,omar.outassafte@ensem.ac.ma \\ Said57.rifai@gmail.com

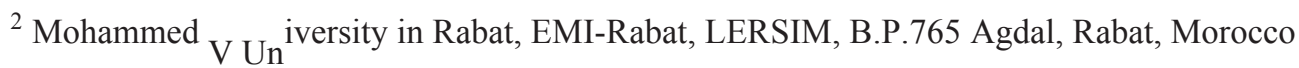 \\ e-mail: rhali.benamer@gmail.com
}

\begin{abstract}
The thermal non-linear vibrational behavior of functional graded beams is analyzed using Euler-Bernoulli beam theory and Hamilton's theorem, combined with spectral analysis. A set of non-linear equations is derived based on the von Kármán deformation-displacement relationship and the properties of the functional graded material are assumed to be temperature dependent and to follow a simple power distribution in the thickness direction. Numerical solutions of the non-linear dynamic equations of functional graded beams are obtained by an approximate method called the second formulation. In addition, numerical examples were performed to highlight the accuracy of the method used in this study, and the results are very consistent with those found in the literature. In the numerical examples, the influences played by thermal environmental conditions and volume fraction index are discussed in detail.
\end{abstract}

Keywords: Functionally graded beams, Non-linear free vibration, Thermal environment, Second formulation. 


\section{INTRODUCTION}

Functionally graded materials (FGM) are composed of a mixture of ceramic and metal or a combination of different materials. The FGM ceramic provides a barrier against thermal effects and protects the metal from corrosion and oxidation, and the FGM is hardened and strengthened by the metal component. Currently, FGM has been developed as a general structural element in extremely high temperature environments and has been widely used in electronics, chemistry, optics, biology, medical engineering and many other fields.

Due to the above-mentioned advantageous characteristics, many studies have been conducted on the following topics, which are the static and dynamic behavior of the FGM structure. Xiang and Shi [1] proposed an analytical solution to analyze the thermo-elasticity of FGM beams embedded in piezoelectric layers. Assuming a cantilevered beam, he used the Airy stress function method to obtain an accurate solution. Ebrahimi et al. [2] reported an analytical method to control the vibration of an FGM beam containing two piezoelectric layers. A theoretical model is based on the Kirchhoff's-Love hypothesis, which has a non-linear geometric von-Karman-type deformation. Fu and colleagues [3] studied the non-linear analysis of buckling, free vibration, active control and dynamic stability of functionally graded piezoelectric beams in a thermal environment. Based on Hamilton's principle, a non-linear guidance equation is established. Falsone and La Valle [4] solved the differential equations governing the axial equilibrium and bending in the Euler-Bernoulli and Timoshenko theory of an FGM beam. This analysis is obtained in both cases of material variation in the transverse and axial directions. Kiani et al. [5] studied the thermal buckling of piezoelectric FGM beams, in which the piezoelectric layer is bonded to the surface and subjected to a constant thermal load and tension. Bodaghi and Shakeri [6] analytically studied the free vibration and dynamic response of a cylindrical piezoelectric FGM panel, which is simply supported and subjected to timedependent explosive pulses. In recent years, a lot of research has been done on free and forced non-linear vibrations. Based on the Euler-Bernoulli beam theory and von Kármán's non-linear kinematics, and using Hamilton's principle, Benamar et al. [7] developed a theory and a method to analyze the vibrational response of isotropic beams. El khouddar et al [8] studied the free and forced non-linear vibrations of laminated composite beams under different boundary conditions, using the Euler-Bernoulli beam theory and the Green-Lagrang nonlinearity. From the Euler-Bernoulli beam theory, Chajdi et al [9] examined the forced nonlinear vibrations of an FGM beam with multiple cracks. Based on the Euler-Bernoulli beam theory, Outassafte et al [10], [11] contributed to the geometrically non-linear free vibration of a fixed-ended arch. Currently, many results have been obtained when studying the dynamic mechannel properties of FGM beams, but most of them are based on linear theory. Due to the large displacement of the structure in engineering practice, the geometric non-linearity must be taken into account, otherwise it will lead to serious errors. At the same time, the analysis under thermal loading will affect the non-linear vibration of the FGM structure. Therefore, it is necessary to study the non-linear vibration of the FGM beam under thermal loading in more detail.

In the present work, the problem of geometrically non-linear free vibrations of FGM beams in a thermal environment with fixed ends is studied. In this analysis, the material properties change continuously through the thickness of the beam according to the power law, and change with temperature changes. The Hamiltonian principle is used to establish the governing equation of the beam under thermal load, and the second formula is used to obtain the analytical solution of the non-linear free vibration problem. Important conclusions have been drawn. 


\section{BASIC EQUATIONS}

Consider an FGM beam of rectangular cross-section with a length of $L$ and a thickness of $h$. This beam is made of a mixture of ceramics and metals. The coordinate system is shown in Figure 1 . The material properties, namely Young's modulus $E$, Poisson's ratio $v$, thermal conductivity $\kappa$, and coefficient of thermal expansion $\alpha$, depend on temperature and vary with thickness.

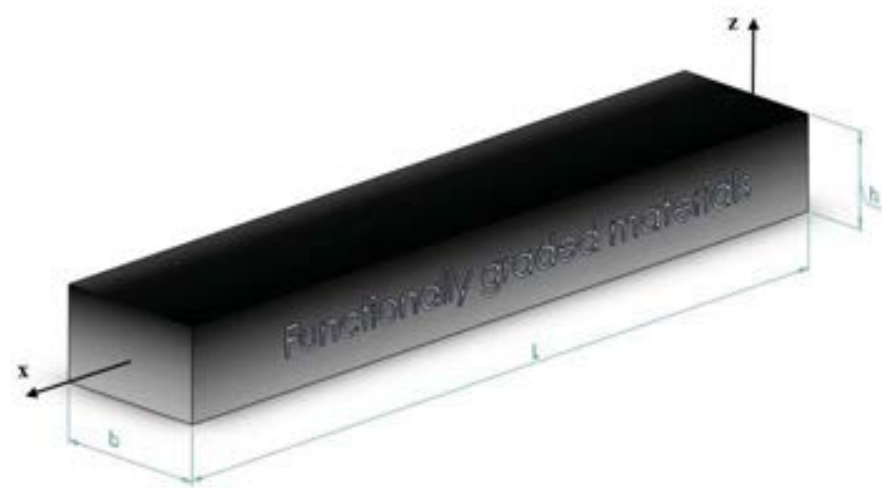

Figure 1: Coordinates and geometry of the FGM beam.

The effective material properties $P$ of the FGM layer, namely the Young's modulus $E$, Poisson's ratio $v$, thermal conductivity $\kappa$ and coefficient of thermal expansion $\alpha$, can be expressed as follows:

$$
P(z, T)=P_{m}+\left(P_{c}-P_{m}\right)\left(\frac{1}{2}+\frac{z}{h}\right)^{k}
$$

The characteristic $P$ of the constituent material depends on the temperature and can be written:

$$
P=P_{0}\left(P_{-1} T^{-1}+1+P_{1} T+P_{2} T^{2}+P_{3} T^{3}\right)
$$

The temperature distribution on the beam is considered as uniform and can reach $\Delta T=T-T_{0}$ to deform the beam. Where $T_{0}$ is the reference temperature of the beam in the unstressed state.

\section{1 linear vibration analysis}

Considering the mid-plane stretch and ignoring the axial inertia, the equations of motion to control the axial and lateral vibration of FGM beams are often considered in the literature and have been adopted in reference [12]:

$$
\begin{gathered}
\frac{\partial N_{x}}{\partial x}=0 \\
\frac{\partial^{2} M_{x}}{\partial x^{2}}+\frac{\partial}{\partial x}\left(N_{x} \frac{\partial w}{\partial x}\right)=\mathrm{I}_{0} \frac{\partial^{2} w}{\partial t^{2}}
\end{gathered}
$$

$N x$ and $M x$ are respectively the axial internal force and the bending moment acting at the mid-plane of the beam are defined as follows:

$$
N_{x}=A_{11} \frac{\partial u}{\partial x}-B_{11} \frac{\partial^{2} w}{\partial x^{2}}-N_{x}^{T}
$$




$$
M_{x}=B_{11} \frac{\partial u}{\partial x}-D_{11} \frac{\partial^{2} w}{\partial x^{2}}-M_{x}^{T}
$$

Where $I_{0}$ is the inertia of the beam:

$$
\mathrm{I}_{0}=\int_{-h / 2}^{h / 2} \rho_{f} d z
$$

Where $N_{x}^{\top}$ and $M_{x}^{\top}$ are the resultant and the moment of the thermal force, which are calculated using the following relations:

$$
N_{x}^{T}=\int_{-h / 2}^{h / 2} E \alpha \Delta T d z, M_{x}^{T}=\int_{-h / 2}^{h / 2}\left(z-z_{0}\right) E \alpha \Delta T d z
$$

In equations (5) and (6), $A_{11}, B_{11}$ and $D_{11}$ are extension-extension, bending-extension and bending-bending coupling coefficients, respectively, which can be evaluated using the wellknown classical theory of FGM beams [13]. Their expressions are defined as follows:

$$
A_{11}=\int_{-\frac{h}{2}}^{\frac{h}{2}} E d z, \quad B_{11}=\int_{-\frac{h}{2}}^{\frac{h}{2}} E\left(z-z_{0}\right) d z, \quad D_{11}=\int_{-\frac{h}{2}}^{\frac{h}{2}} E\left(z-z_{0}\right)^{2} d z
$$

The axial equation (1) of equilibrium is then given by :

$$
N_{x}=A_{11} \frac{\partial u}{\partial x}-B_{11} \frac{\partial^{2} w}{\partial x^{2}}-N_{x}^{T}=N_{x 0}
$$

Considering the fixed ends (i.e. $u=0$, at $x=0$ and $L$ ), the integration of Eq (10) along the $\mathrm{x}$-axis leads to:

$$
0=\int_{0}^{L} \frac{\partial u}{\partial x} d x=u(L)-u(0)=\frac{1}{A_{11}} \int_{0}^{L}\left[\left(N_{x 0}+N_{x}^{T}+B_{11} \frac{\partial^{2} w}{\partial x^{2}}\right)\right\rfloor d x
$$

Also:

$$
N_{x 0}=\frac{A_{11}}{L} \int_{0}^{L}\left\lfloor-\frac{B_{11}}{A_{11}} \frac{\partial^{2} w}{\partial x^{2}}\right\rfloor d x-N_{x}^{T}
$$

By introducing equation (12) into equation (6), the bending moment can be rewritten as follows:

$$
M_{x}=B_{11}\left\lfloor\frac{N_{x 0}+N_{x}^{T}}{A_{11}}+\frac{B_{11}}{A_{11}} \frac{\partial^{2} w}{\partial x^{2}}\right\rfloor-D_{11} \frac{\partial^{2} w}{\partial x^{2}}-M_{x}^{T}
$$

Taking $N_{x}^{\top}$ and $M_{x}^{\top}$ as constants along the $\mathrm{x}$-axis, we can obtain the following linear steering equation for the FGM beam by inserting equations (12) and (13) into equation (4).

$$
D_{11} \frac{\partial^{4} w}{\partial x^{4}}+\left(N^{T}\right) \frac{\partial^{2} w}{\partial x^{2}}+\mathrm{I}_{0} \frac{\partial^{2} w}{\partial t^{2}}=0
$$

Equation (14) can be written in a slightly less complicated way, the result is:

$$
w^{\prime \prime \prime \prime}+\lambda w^{\prime \prime}-\beta^{4} w=0
$$

In formula (15), the new symbol indicates the following functional relationship: 


$$
\lambda=\frac{N^{T}}{D_{11}}, \quad \beta^{2}=\frac{\omega}{c}, c^{2}=\frac{D_{11}}{\mathrm{I}_{0}}
$$

Where $x^{*}$ is a dimensionless coordinate, which can be written: $x^{*}=\frac{x}{L}$. Equation (15) is an ordinary differential equation of order 4 with constant coefficients whose general solution is given by:

$$
\begin{aligned}
& w_{i}\left(x^{*}\right)=A \sin \left(\sqrt{\frac{1}{2} \lambda+\frac{1}{2} \sqrt{\lambda^{2}+4 \beta_{i}^{4}}} x^{*} L\right)+B \cos \left(\sqrt{\frac{1}{2} \lambda+\frac{1}{2} \sqrt{\lambda^{2}+4 \beta_{i}^{4}}} x^{*} L\right)+ \\
& C \sinh \left(\sqrt{-\frac{1}{2} \lambda+\frac{1}{2} \sqrt{\lambda^{2}+4 \beta_{i}^{4}}} x^{*} L\right)+D \cosh \left(\sqrt{-\frac{1}{2} \lambda+\frac{1}{2} \sqrt{\lambda^{2}+4 \beta_{i}^{4}}} x^{*} L\right)
\end{aligned}
$$

$\mathrm{i}$ changes from 1 to $\mathrm{n}$, where $\mathrm{n}$ is the number of functions.

\subsection{Non-linear vibration analysis}

Using the displacement fields from the Euler-Bernoulli theory and assuming that the FGM beam has large vibration amplitudes, the Von-Karman relation can be written as follows:

$$
\varepsilon_{x x}=\frac{\partial u}{\partial x}-\left(z-z_{0}\right) \frac{\partial^{2} w}{\partial x^{2}}+\frac{1}{2}\left(\frac{\partial w}{\partial x}\right)^{2}
$$

The kinetic energy Te of an FGM beam in vibration is equal to:

$$
T_{e}=\frac{\mathrm{I}_{0}}{2} \int_{0}^{L}\left(\frac{\partial w}{\partial t}\right)^{2} d x
$$

The potential energy $V$ can be written in terms of transverse displacement w and longitudinal displacement for our beam as:

$$
V=\frac{1}{2} \int_{0}^{L} N_{x}\left(\frac{\partial u}{\partial x}+\frac{1}{2}\left(\frac{\partial w}{\partial x}\right)^{2}\right)+M_{x}\left(-\frac{\partial^{2} w}{\partial x^{2}}\right) d x
$$

Using the generalized parameterization that corresponds to the transverse displacement of the beam we have [14], [15]:

$$
w=a_{i} w_{i}(x) \sin \omega t
$$

According to Hamilton's principle, the non-linear algebraic equations of the dynamic behavior of the structure are calculated using the tensor notation:

$$
a_{i} k_{i q}+\frac{3}{2} a_{i} a_{j} a_{k} b_{i j k q}-\omega^{2} a_{i} m_{i q}=0, i=1, \ldots, n
$$

To perform a general parametric study, the following dimensionless formulation is used:

$$
x^{*}=\frac{x}{L}, w_{i}(x)=r w_{i}^{*}\left(x^{*}\right), r^{2}=\frac{\int_{-h / 2}^{h / 2} z^{2} d z}{\int_{-h / 2}^{h / 2} d z}
$$


$r$ is the radius of gyration of the piezoelectric FGM beam. The numerical solution of equation (22) can be obtained by using the second formula described in [16]. This approximation consists of ignoring the second-order terms provided by the relevant mode. As mentioned in the reference, in the non-linear expression $\mathrm{a}_{\mathrm{i}} \mathrm{a}_{\mathrm{j}} \mathrm{a}_{\mathrm{k}} \mathrm{b}_{\mathrm{ijkq}}$ of equation (22), the second order term of $\varepsilon_{\mathrm{i}}$ will be ignored.

\section{NUMERICAL RESULTS AND DISCUSSIONS}

In this section, the FGM beam is chosen for the material Si3N4 / SUS304, this beam has a length of $L=200 \mathrm{~mm}$ and a thickness of $h=10 \mathrm{~mm}$. Table 1 shows the characteristics of Young's modulus $\mathrm{E}$ (in Pa), thermal expansion coefficient $\alpha$ (in $\mathrm{K}$ ) and thermal conductivity $\kappa$ (in W/mK). For the Poisson's ratio $v$ of the FGM layer is assumed to be constant equal to 0.28 . It should also be noted that the upper surface of the substrate $(z=h / 2)$ is ceramic rich and the lower surface $(z=-h / 2)$ is metal rich. In addition, the temperature Tm of the lower surface of the FGM beam is assumed to be $300 \mathrm{~K}$, and the temperature Tc of the upper surface is variable.

Table 1. Coefficients material properties as a function of temperature for Si3N4 and SUS304.

\begin{tabular}{ccccccc}
\hline Materials & Properties & $\mathrm{P}_{0}$ & $\mathrm{P}_{-1}$ & $\mathrm{P}_{1}$ & $\mathrm{P}_{2}$ & $\mathrm{P}_{3}$ \\
\hline \multirow{2}{*}{ Si3N4 } & $\mathrm{E}_{\mathrm{c}}(\mathrm{Pa})$ & $348.43 \mathrm{e}+9$ & 0 & $-3.07 \mathrm{e}-4$ & $2.160 \mathrm{e}-7$ & $-8.964 \mathrm{e}-11$ \\
& $\alpha_{\mathrm{c}}(1 / \mathrm{K})$ & $5.8723 \mathrm{e}-6$ & 0 & $9.095 \mathrm{e}-4$ & 0 & 0 \\
& $\kappa_{\mathrm{c}}(\mathrm{W} / \mathrm{mK})$ & 13.723 & 0 & $-1.032 \mathrm{e}-3$ & $5.466 \mathrm{e}-7$ & $-7.876 \mathrm{e}-11$ \\
\multirow{2}{*}{ SUS304 } & $\mathrm{E}_{\mathrm{m}}(\mathrm{Pa})$ & $201.04 \mathrm{e}+9$ & 0 & $3.079 \mathrm{e}-4$ & $-6.534 \mathrm{e}-7$ & 0 \\
& $\alpha_{\mathrm{m}}(1 / \mathrm{K})$ & $12.33 \mathrm{e}-6$ & 0 & $8.086 \mathrm{e}-4$ & 0 & 0 \\
& $\kappa_{\mathrm{m}}(\mathrm{W} / \mathrm{mK})$ & 15.379 & 0 & $-1.264 \mathrm{e}-3$ & $2.092 \mathrm{e}-6$ & $-7.223 \mathrm{e}-10$ \\
\hline
\end{tabular}

Before further investigation of the non-linear behaviors of the FGM beam, the results between the present method and previous work [17] are compared to prove the accuracy of the proposed method. Table 2 lists the dimensionless linear eigenfrequencies $\left(\omega_{1} \cdot L^{2} / h \cdot \sqrt{\rho_{b} / E_{b}}\right)$ of the FGM beam considering the clamped-clamped boundary condition when the length-toheight ratio is $L / h=100$. The results of these comparisons, considering the material properties for the upper $\left(E_{t}\right.$ and $\rho_{\mathrm{t}}$ : ceramic) and lower $\left(E_{b}\right.$ and $\rho_{b}$ : aluminium) surfaces are as follows [17]: $E_{t}=380 \mathrm{Gpa}, \rho_{t}=3960 \mathrm{Kg} / \mathrm{m}^{3}, E_{b}=70 \mathrm{Gpa}, \rho_{b}=2702 \mathrm{Kg} / \mathrm{m}^{3}$

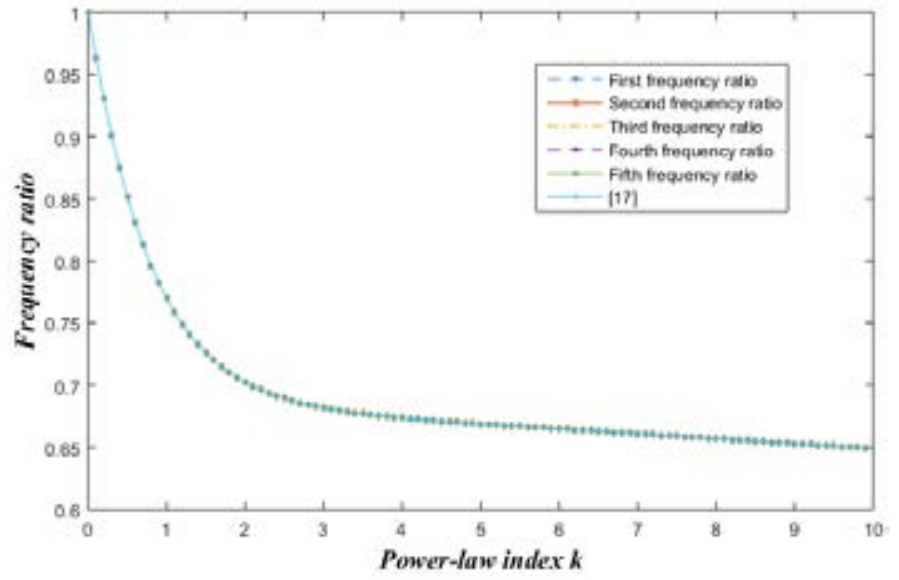

Figure 2: Comparisons of the first five non-dimensional eigenfrequencies of the FGM beam with clamping boundary conditions and for different values of the power index. 
It can be seen from Table 2 that the results obtained in this study are in perfect agreement with the results given in the literature, which verifies the effectiveness of the shape function used in this work.

Table 2. Dimensionless linear nature frequency of FGM beam for different volume fraction exponent k.

\begin{tabular}{|c|c|c|c|c|c|c|}
\hline \multirow{2}{*}{$\mathrm{k}$} & & \multicolumn{5}{|c|}{ Modes } \\
\hline & & 1 & 2 & 3 & 4 & 5 \\
\hline \multirow{2}{*}{0} & Present & 12.430 & 34.264 & 67.171 & 111.038 & 165.871 \\
\hline & [17] & 12.430 & 34.258 & 67.144 & 110.96 & 165.69 \\
\hline \multirow{2}{*}{0.1} & Present & 11.974 & 33.009 & 64.711 & 106.971 & 159.796 \\
\hline & [17] & 11.974 & 33.003 & 64.685 & 106.90 & 159.62 \\
\hline \multirow{2}{*}{0.2} & Present & 11.565 & 31.880 & 62.498 & 103.313 & 154.332 \\
\hline & {$[17]$} & 11.565 & 31.875 & 62.473 & 103.24 & 154.16 \\
\hline \multirow{2}{*}{0.5} & Present & 10.584 & 29.175 & 57.195 & 94.546 & 141.236 \\
\hline & [17] & 10.583 & 29.170 & 57.171 & 94.478 & 141.08 \\
\hline \multirow{2}{*}{1} & Present & 9.5685 & 26.375 & 51.707 & 85.474 & 127.684 \\
\hline & {$[17]$} & 9.5680 & 26.371 & 51.685 & 85.410 & 127.53 \\
\hline \multirow{2}{*}{2} & Present & 8.7316 & 24.069 & 47.185 & 77.999 & 116.517 \\
\hline & [17] & 8.7311 & 24.064 & 47.162 & 77.934 & 116.37 \\
\hline \multirow{2}{*}{5} & Present & 8.3137 & 22.917 & 44.926 & 74.266 & 110.941 \\
\hline & [17] & 8.3132 & 22.912 & 44.904 & 74.201 & 110.79 \\
\hline \multirow{2}{*}{10} & Present & 8.0676 & 22.238 & 43.597 & 72.068 & 107.657 \\
\hline & [17] & 8.0672 & 22.234 & 43.576 & 72.008 & 107.52 \\
\hline
\end{tabular}

Taking into account the material characteristics (see Table 1 [18]), the influence of the thermal load and the volume fraction index on the first three modes of the linear dimensionless eigenfrequency of the FGM beam is studied by considering the boundary condition clamped-clamped. It can be seen from Table 3 that when the temperature of the upper surface of the beam $T c$ increases, and when the temperature of the lower surface Tm remains constant $(T m=300 \mathrm{~K})$, the dimensionless eigenfrequency of the beam is stripped, which indicates the temperature-independent material properties have overestimated the stiffness of the structure. As shown in Table 3, in a high-temperature environment, the material properties related to the beam temperature must be considered. In addition, it should be noted that as the volume fraction index $\mathrm{k}$ increases, the frequency decreases due to the fact that the Young's modulus of SUS304 is lower than that of Si3N4.

Table 3. Dimensionless fundamental frequency of the FGM beam under thermal loading with temperature dependent material properties.

\begin{tabular}{|c|c|c|c|c|c|c|c|}
\hline \multirow{2}{*}{ Modes } & \multirow{2}{*}{$\operatorname{Tc}(\mathrm{K})$} & \multicolumn{6}{|c|}{ Volume fraction exponent $\mathrm{k}$} \\
\hline & & 0 & 0.2 & 0.5 & 2 & 5 & 10 \\
\hline \multirow{3}{*}{1} & 300 & 14.930 & 12.103 & 10.279 & 8.094 & 7.361 & 7.012 \\
\hline & 400 & 14.162 & 11.374 & 9.576 & 7.433 & 6.717 & 6.369 \\
\hline & 500 & 13.353 & 10.565 & 8.765 & 6.632 & 5.923 & 5.566 \\
\hline \multirow{3}{*}{2} & 300 & 41.156 & 33.363 & 28.335 & 22.311 & 20.293 & 19.331 \\
\hline & 400 & 40.064 & 32.346 & 27.369 & 21.420 & 19.430 & 18.473 \\
\hline & 500 & 39.117 & 31.380 & 26.388 & 20.445 & 18.464 & 17.497 \\
\hline \multirow{3}{*}{3} & 300 & 80.682 & 65.405 & 55.548 & 43.740 & 39.783 & 37.896 \\
\hline & 400 & 79.384 & 64.224 & 54.447 & 42.748 & 38.829 & 36.954 \\
\hline & 500 & 78.535 & 63.306 & 53.481 & 41.754 & 37.836 & 35.945 \\
\hline
\end{tabular}

Figure 3 shows the influence of the volume fraction k of the Si3N4 / SUS304 FGM beam on the ratio of non-linear to linear frequency $\left(\omega_{N L} / \omega_{L}\right)$, which is a function of the dimensionless vibration amplitude $W \max / r$. The volume fraction significantly affects the Backbone curve. 
On the other hand, when the exponential of the volume fraction diminishes, the frequency ratio increases. All these FGM beams with different volume fractions show typical hardening behavior, i.e., the non-linear frequency increases with increasing vibration amplitude. The effects of uniformly increasing the temperature of the FGM beam with a volume fraction index $\mathrm{k}=1$ and clamped ends on the relationship between the non-linear to linear frequency are shown in Figure 4. In this example, the temperature of the bottom surface $T m$ remains constant $(T m=300 \mathrm{~K})$, while the temperature of the top surface $T c$ varies $(T c=300,400$ and 500 $\mathrm{K})$. The results in Figure 4 show that the curves of the non-linear to linear frequency ratios tend to increase as $T c$ increases, and the non-linear effect tends to be higher as $T c$ increases. Figure 5 illustrates the effect of simultaneous change in temperature and volume fraction on the non-linear vibration behavior of FGM Si3N4/SUS304 beams. In Figure 5, it is found that increasing the volume fraction $(\mathrm{k}=0,1$ and 5$)$ and increasing the temperature of the top surface $(T c=300$ and $500 \mathrm{~K})$ result in an increase in the ratio of non-linear to linear frequency. It is also interesting to note that as the temperature increases, the effect of the volume fraction exponent $\mathrm{k}$ on the frequency ratio decreases.

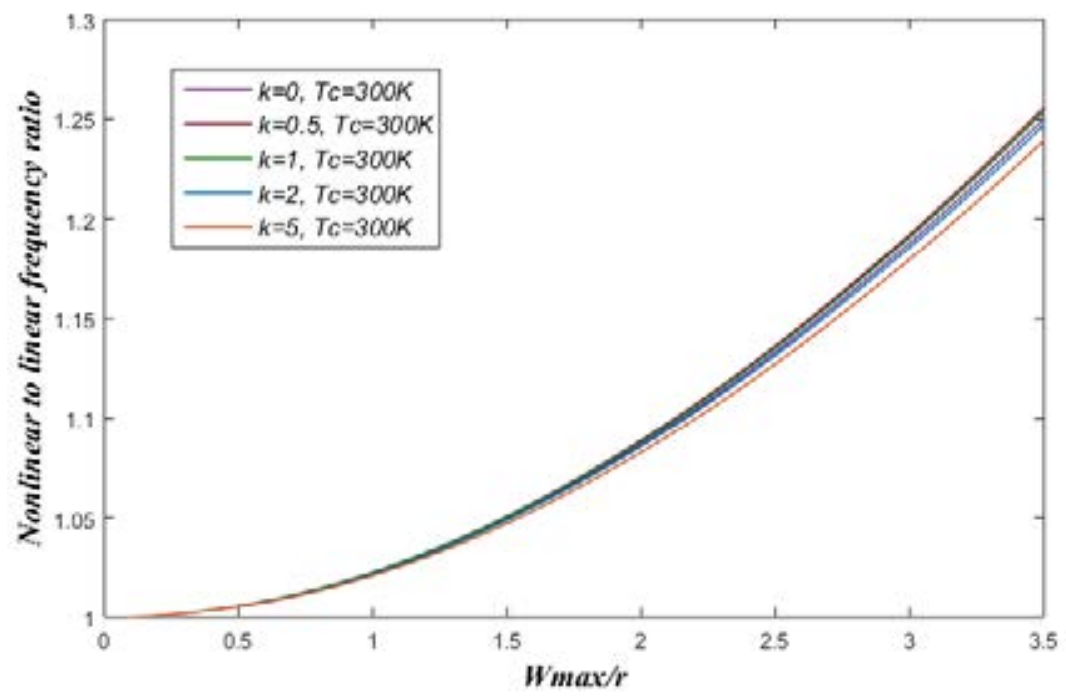

Figure 3: Influence of volume fraction $\mathrm{k}$ on the ratio of non-linear to linear frequency of FGM beams with thermal load $T c=300 \mathrm{~K}$.

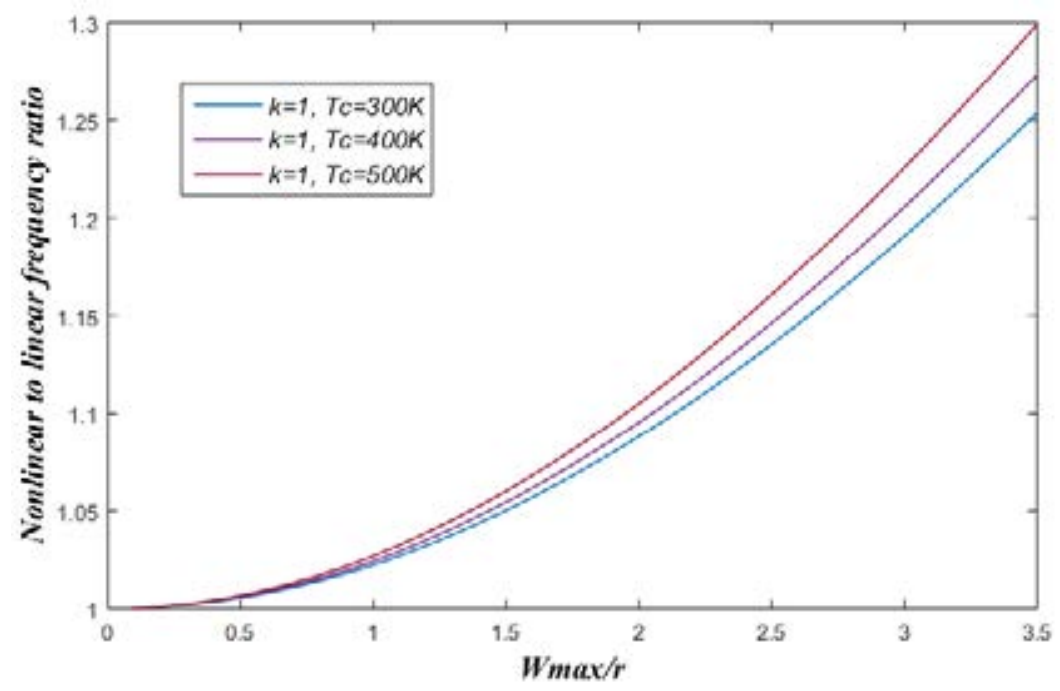

Figure 4: Influence of the thermal load Tc on the ratio of the non-linear frequency to the linear frequency of FGM beams with volume fraction $\mathrm{k}=1$. 


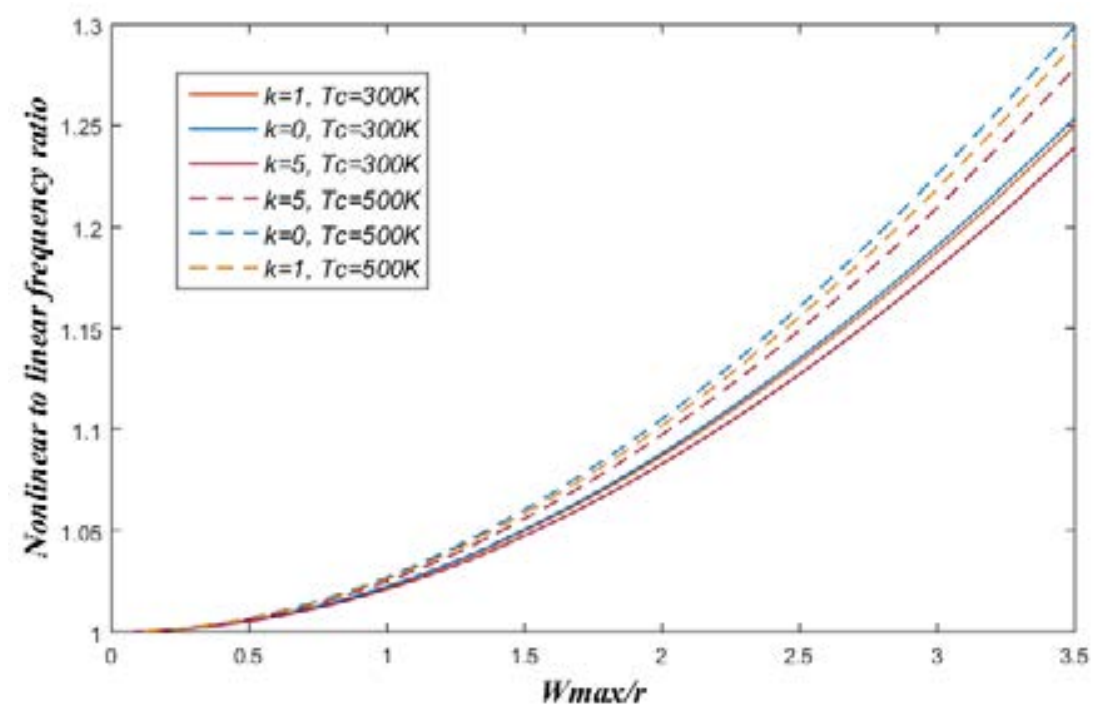

Figure 5: Influence of thermal loading on the ratio of non-linear to linear frequency of FGM beams with different volume fraction indices.

\section{CONCLUSIONS}

The behavior of clamped FGM beams under free vibration in a thermodynamic environment is studied. The geometrically non-linear vibrational equations are determined in this analysis using an analytical approach based on the Euler-Bernoulli beam model and Hamilton's principle. The effective material properties of FGMs are assumed to be temperature dependent and to follow a simple power distribution in the thickness direction. The effects of volume fraction exposure, thermal loading, and thermal properties of constituent materials on non-linear vibration studies of FGM beams were examined in a parametric study. Numerical results indicate that the volume fraction affects the natural and non-linear frequencies in the ambient temperature fields. The volume fraction has an effect on the non-linear free vibration behavior of an FGM beam, and this effect weakens with increasing temperature. Furthermore, as the temperature increases, the non-linear effect increases, and the relationship between non-linear frequency and non-linear frequency as a function of nondimensional vibration amplitudes increases accordingly.

\section{REFERENCES}

[1] H. J. Xiang and Z. F. Shi, 'Static analysis for functionally graded piezoelectric actuators or sensors under a combined electro-thermal load', European Journal of Mechanics A/Solids, vol. 28, no. 2, pp. 338-346, Mar. 2009, doi: 10.1016/j.euromechsol.2008.06.007.

[2] F. Ebrahimi, M. H. Naei, and A. Rastgoo, 'Geometrically nonlinear vibration analysis of piezoelectrically actuated FGM plate with an initial large deformation', J Mech Sci Technol, vol. 23, no. 8, pp. 2107-2124, Aug. 2009, doi: 10.1007/s12206-009-0358-8.

[3] Y. Fu, J. Wang, and Y. Mao, 'Nonlinear vibration and active control of functionally graded beams with piezoelectric sensors and actuators', Journal of Intelligent Material Systems and Structures, vol. 22, no. 18, pp. 2093-2102, Dec. 2011, doi: $10.1177 / 1045389 X 11425277$.

[4] G. Falsone and G. La Valle, 'A homogenized theory for functionally graded EulerBernoulli and Timoshenko beams', Acta Mech, vol. 230, no. 10, pp. 3511-3523, Oct. 2019, doi: 10.1007/s00707-019-02493-w. 
[5] Y. Kiani, S. Taheri, and M. R. Eslami, 'Thermal Buckling of Piezoelectric Functionally Graded Material Beams', Journal of Thermal Stresses, vol. 34, no. 8, pp. 835-850, Aug. 2011, doi: 10.1080/01495739.2011.586272.

[6] M. Bodaghi and M. Shakeri, 'An analytical approach for free vibration and transient response of functionally graded piezoelectric cylindrical panels subjected to impulsive loads', Composite Structures, vol. 94, no. 5, pp. 1721-1735, Apr. 2012, doi: 10.1016/j.compstruct.2012.01.009.

[7] R. Benamar, M. M. K. Bennouna, and R. G. White, 'The effects of large vibration amplitudes on the mode shapes and natural frequencies of thin elastic structures part I: Simply supported and clamped-clamped beams', Journal of Sound and Vibration, vol. 149, no. 2, pp. 179-195, Sep. 1991, doi: 10.1016/0022-460X(91)90630-3.

[8] Y. E. khouddar, A. Adri, S. Rifai, and R. Benamar, 'Geometrically non-linear forced vibrations of Euler-Bernoulli laminated composite beams', J. Phys.: Conf. Ser., vol. 1896, no. 1, p. 012016, Apr. 2021, doi: 10.1088/1742-6596/1896/1/012016.

[9] M. Chajdi, A. Ahmed, K. E. Bikri, and R. Benamar, 'Analysis of the associated stress distributions to the nonlinear forced vibrations of functionally graded multi-cracked beams', Diagnostyka, vol. 22, no. 1, pp. 101-112, Feb. 2021, doi: 10.29354/diag/133702.

[10] O. Outassafte, A. Adri, Y. el Khouddar, R. Said, and R. Benamar, 'Geometrically Non-Linear Free In-Plane Vibration Of Circular Arch Elastically Restrained Against Rotation At The Two Ends', International Journal of Engineering Trends and Technology, vol. 69, pp. 85-95, Mar. 2021, doi: 10.14445/22315381/IJETT-V69I3P215.

[11] O. Outassafte, A. Adri, R. Said, and R. Benamar, 'Geometrically nonlinear free vibration of Euler-Bernoulli shallow arch', Journal of Physics: Conference Series, vol. 1896, p. 012013, Apr. 2021, doi: 10.1088/1742-6596/1896/1/012013.

[12] L.-L. Ke, J. Yang, and S. Kitipornchai, 'An analytical study on the nonlinear vibration of functionally graded beams', Meccanica, vol. 45, no. 6, pp. 743-752, Dec. 2010, doi: 10.1007/s11012-009-9276-1.

[13] Z. Wu, Y. Zhang, G. Yao, and Z. Yang, 'Nonlinear primary and super-harmonic resonances of functionally graded carbon nanotube reinforced composite beams', International Journal of Mechanical Sciences, vol. 153-154, pp. 321-340, Apr. 2019, doi: 10.1016/j.ijmecsci.2019.02.015.

[14] H. Fakhreddine, A. Adri, M. Chajdi, S. Rifai, and R. Benamar, 'A multimode approach to geometrically non-linear forced vibration of beams carrying point masses', Diagnostyka, vol. 21, no. 4, pp. 23-33, Nov. 2020, doi: 10.29354/diag/128603.

[15] I. el Hantati, A. Adri, H. Fakhreddine, R. Said, and R. Benamar, 'A Multimode Approach to Geometrically Nonlinear Free and Forced Vibrations of Multistepped Beams', Shock and Vibration, vol. 2021, pp. 1-18, Apr. 2021, doi: 10.1155/2021/6697344.

[16] M. El kadiri, R. Benamar, and R. G. White, 'IMPROVEMENT OF THE SEMIANALYTICAL METHOD, FOR DETERMINING THE GEOMETRICALLY NONLINEAR RESPONSE OF THIN STRAIGHT STRUCTURES. PART I: APPLICATION TO CLAMPED-CLAMPED AND SIMPLY SUPPORTED-CLAMPED BEAMS', Journal of Sound and Vibration, vol. 249, no. 2, pp. 263-305, Jan. 2002, doi: 10.1006/jsvi.2001.3808.

[17] J. W. Lee and J. Y. Lee, 'Free vibration analysis of functionally graded BernoulliEuler beams using an exact transfer matrix expression', International Journal of Mechanical Sciences, vol. 122, pp. 1-17, Mar. 2017, doi: 10.1016/j.ijmecsci.2017.01.011.

[18] J. N. Reddy and C. D. Chin, 'Thermomechanical Analysis of Functionally Graded Cylinders and Plates', Journal of Thermal Stresses, vol. 21, no. 6, pp. 593-626, Sep. 1998, doi: 10.1080/01495739808956165. 